\title{
Improving the quality of the NHS workforce through values and competency-based selection
}

McGuire C, Rankin J, Matthews L et al (2016) Improving the quality of the NHS workforce through values and competency-based selection. Nursing Management. 23, 4, 26-33. Date of submission: II March 2016; date of acceptance: 23 May 20l6. doi: I0.7748/nm.20l6.el502

\section{Clare McGuire \\ is programme manager, Leading Better Care, University of the West of Scotland, Hamilton}

\section{Jean Rankin \\ is professor, University of the} West of Scotland

\section{Lynsay Matthews}

is research associate,

University of Glasgow

\section{Marie Cerinus}

is development adviser NHS Lanarkshire

\section{Swati Zaveri \\ is post-doctoral research \\ fellow, University of the \\ West of Scotland \\ Correspondence \\ clare.mcguire@uws.ac.uk \\ Review \\ This article has been subject to double-blind review and has been checked using} antiplagiarism software

Conflict of interest None declared

\begin{abstract}
Robust selection processes are essential to ensure the best and most appropriate candidates for nursing, midwifery and allied health professional (NMAHP) positions are appointed, and subsequently enhance patient care. This article reports on a study that explored interviewers' and interviewees' experiences of using values and competency-based interview (VCBI) methods for NMAHPs. Results suggest that this resource could have a positive effect on the quality of the NMAHP workforce, and therefore on patient care. This method of selection could be used in other practice areas in health care, and refinement of the resource should focus on supporting interview panels to develop their VCBI skills and experience.
\end{abstract}

\section{Keywords}

care and compassion, health professionals, recruitment, staff selection methods, values and competencies

\section{Background and literature review}

High quality patient care is delivered by health professionals with caring and compassionate values (King's Fund 2013), and over the years these values have remained relatively unchanged (Table 1) (Yancey 1997, Ersoy and Altun 1998, Hall 1996).

Recent studies highlight the importance of dignity and respect (Gallagher 2004), and suggest adding altruism and emotional intelligence to staff selection criteria (Rankin 2013, Smith et al 2013).

Clinical competency is a common component of interviews for nursing, midwifery and allied health professionals (NMAHPs), but research suggests that few selection processes and appointments include assessment of personal attributes (Highhouse 2008, Burke et al 2014), professionalism or behaviour (Newton et al 2014). This could be reflected in complaints from patients, which are often based on the absence of empathy, compassion, manners, patience and non-verbal communication (Parliamentary and Health Service Ombudsman 2011).

This is supported by the report of the Mid-Staffordshire NHS Foundation Trust Public Inquiry (Francis 2013), which highlighted that poor quality care was delivered by staff who lacked the values and competencies that should underpin the NHS. Appointing appropriate individuals who can positively affect patients' experiences (Cerinus and Shannon 2014), and who possess a strong commitment to the health service, is therefore essential.

Individuals' commitment to organisations is governed by a number of factors: their belief in and acceptance of the organisation's values; a willingness to exert effort on the organisation's behalf; and a desire to remain in the profession (Gutierrez et al 2012).

Recent government policies highlight the importance of this. For example, the Scottish government's 2020 Vision (Scottish Government 2013) aims to ensure the NHS workforce in Scotland has the values, professionalism and clinical competencies needed to be 'amongst the best in the world'.

Higher education institutions in England have been required to adopt values-based recruitment since April 2015 (Health Education England 2014). This development recognises the need to establish values at the earliest opportunity when recruiting in the caring professions, to support excellence in patient care. Values-based selection in higher education is under development in Scotland, while it remains only a recommendation for NHS recruitment in England.

\section{Study context}

Staff selection was identified as an area that required development through the local 
Leading Better Care (LBC) programme, a collaboration between NHS Lanarkshire and University of the West of Scotland (UWS) (McGuire and Ray 2014).

Exploratory work in NMAHP selection processes identified a lack of consistency and clarity in interview preparation and questioning, while the lack of a robust scoring system made it challenging to assess interview candidates against organisational values (Cerinus and Shannon 2014).

Values and attributes are considered an indicator of individuals' future behaviours (Gangani et al 2006), and human resource (HR) research has found that selection processes that evaluate people's skills, knowledge and behaviours reflect their ability to perform effectively (Patterson et al 2007).

Local selection of NMAHPs was revised based on findings from this exploratory work, so that a values and competencybased method could be used, which is a more rigorous and robust process that helps select the 'best candidate'. NMAHPs are now guided by a locally designed core competency framework (Table 2), against which they are assessed during the selection process (NHS Lanarkshire 2013a).

To succeed in values and competency-based interviews (VCBIs), candidates are required to provide examples of each competency from their past experiences as part of their applications and interviews; this reflects Gangani et al's (2006) view of the 'best predictor of future behaviour being past behaviour'. This contrasts with prospective questioning, in which candidates are often asked to respond to possible future scenarios.

Senior staff involved in selection were given training in conducting effective VCBIs.

\section{Study}

An exploratory study was designed to gather staff and candidates' experiences of VCBIs, and to assess the resource's potential for supporting the appointment of the most appropriate, and therefore values-based, candidates. It was expected that NHS leaders and managers would gain insight from this study and that these insights would, through reflection, inform their selection methods.

A purposive sampling method was chosen, and data were collected from focus groups, interviews and questionnaires.

\section{Data collection from staff}

Staff experiences of VCBIs were gathered through focus groups and semi-structured interviews. Participants included HR staff,

\section{TABLE I: Values identified in modern healthcare}

\begin{tabular}{|l|l|}
\hline $\begin{array}{l}\text { Values } \\
\text { Human dignity }\end{array}$ & Kindness, respectfulness, honesty, trustworthiness, empathy \\
\hline Justice & Morality, courage, objectivity, willingness to upholding moral and legal principles \\
\hline Truth & Knowledge, realism, curiosity, rationality, inquisitiveness, responsibility, self-confidence \\
\hline Aesthetics & Imagination, appreciation, sensitivity, creativity \\
\hline Freedom & Self-direction, self-discipline, independence, capacity for choice \\
\hline Altruism & Commitment, compassion, generosity, perseverance, benevolence, sympathy \\
\hline Equality & Fairness, commitment to equal rights, privileges and status \\
\hline
\end{tabular}

a VCBI training provider, and senior NHS leaders who had either been an interview panel chair, or interview panel member, for NMAHP selections in the past year. Participants were identified from the VCBI staff training sessions and contacted by email. HR staff who had been involved in implementing VCBIs were identified through an existing working group.

Three focus groups were conducted, one with HR staff and two with senior leaders. One semi-structured interview was also conducted with the VCBI training provider to gain insight from that perspective. Focus groups and interviews lasted for between 45 and 60 minutes. The aim was to support discussions about participants' experience of using VCBIs, their reflections on the benefits and challenges of the resource, and suggestions for future development. A university researcher led each focus group and conducted the interviews.

Data collection from interview candidates An anonymous, paper questionnaire was used to gather candidates' experiences immediately following their interview. They completed this in a private area away from the interview room and before knowing the outcome. A university researcher invited candidates to complete the questionnaire, and reassured them that their responses were anonymous, confidential and would not be shared with the interview panel, or affect the outcome.

The questions were designed to determine whether the VCBI enabled candidates to demonstrate their values, skills and knowledge, highlight the difficulty of responding to VCBI questions, illustrate how they prepared for the VCBI interview and how they might do this differently in future, and collect suggestions for improvements to the approach. 


\section{KEY POINT \\ I've interviewed band 4,5,6 and 7 , and I think it gives you a much better feeling for the person. It gives you a better idea of their character, which is hard to hide in a values and competency based interview. I don't think you get that in a more traditional interview' - study participant}

\section{Analysis}

Focus groups and individual interviews were transcribed and analysed using a systematic thematic analysis framework (Colaizzi 1978), and candidates' responses from the questionnaires were analysed for quantitative and qualitative data. Findings were discussed by the researchers to develop recommendations for future practice.

\section{Ethical approval}

The study was categorised as a service evaluation and was supported by NHS Lanarkshire's research and development department. Standard ethical principles were followed, incorporating participant information, gaining informed consent and protecting data in line with the Data Protection Act 1998.

\section{Findings}

A total of 21 participants provided insight on the use of VCBIs, which included eight HR staff, 12 senior leaders and one VCBI training

\section{TABLE 2: NHS Lanarkshire competency} framework

\begin{tabular}{|c|c|c|}
\hline \multicolumn{2}{|c|}{ Competency } & Skills or qualities required \\
\hline \multirow{8}{*}{ 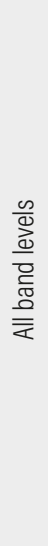 } & 1 & Care and compassion \\
\hline & 2 & Technical or role-specific skills \\
\hline & 3 & Communication abilities \\
\hline & 4 & Person- and people-development skills \\
\hline & 5 & $\begin{array}{l}\text { Understanding of health, safety and } \\
\text { security }\end{array}$ \\
\hline & 6 & Service-development skills \\
\hline & 7 & Understanding of quality \\
\hline & 8 & Understanding of equality and diversity \\
\hline \multirow{8}{*}{ 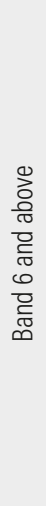 } & 9 & Intellectual flexibility \\
\hline & 10 & Drive to achieve results \\
\hline & 11 & Self-belief \\
\hline & 12 & Drive to achieve improvement \\
\hline & 13 & Personal integrity \\
\hline & 14 & Ability to lead change through people \\
\hline & 15 & Effective strategic influencing skills \\
\hline & 16 & Technical or role-specific skills \\
\hline
\end{tabular}

provider. Four themes with sub-themes were identified (Table 3 ).

Coding of the data was carried out by two researchers independently, and themes were agreed jointly. Both researchers derived a similar number of themes and sub-themes, which demonstrates rigour and reliability.

\section{Theme A: benefits of using VCBIs}

All participants perceived VCBIs as a positive change to the selection process, and the specific benefits they identified are discussed below.

\section{Al. Higher quality of candidates at the application stage}

Candidates were required to provide examples of their values and competencies on the application form. This enabled the selection panel to identify candidates who had prepared their application in relation to VCBI selection, and to identify those with relevant experience. This led to a higher quality of candidates progressing to the interview stage. One participant made the following comment, which refers to the overall improvement noted: 'The way we were doing the selection process before wasn't satisfactory in terms of who we were getting in the door.'

\section{A2. Identification of strong candidates at interview stage}

Participants perceived that the system enabled them to identify strong candidates. VCBIs took around 25 to 30 minutes longer than the previous interview format, which gave more time to ask focused questions about candidates' past experience, values and competencies relevant to the job, and to elaborate on specific points.

Participants also perceived the quality and depth of candidates' responses were a more accurate measure of their personal values and attributes.

One participant said: 'I've interviewed band 4,5,6 and 7, and I think it gives you a much better feeling for the person. It gives you a better idea of their character, which is hard to hide in a VCBI. I don't think you get that in a more traditional interview.'

The participants agreed that providing reallife examples from work and/or life experiences helped evaluate candidates' characters by identifying those who had prepared for a VCBI, and those who responded confidently with 'I did...' rather than 'we did...'. They also perceived that candidates' future conduct could relate to how they responded to challenging situations in the past. 


\section{TABLE 3: Themes and sub-themes identified from focus groups and interviews}

\begin{tabular}{|c|c|c|c|}
\hline $\begin{array}{l}\text { Theme A: benefits of } \\
\text { values and competency- } \\
\text { based interviews (VCBIs) }\end{array}$ & $\begin{array}{l}\text { Theme B: challenges of } \\
\text { conducting VCBls }\end{array}$ & $\begin{array}{l}\text { Theme C: limitations of } \\
\text { VCBls }\end{array}$ & $\begin{array}{l}\text { Theme D: future } \\
\text { refinements of VCBIs }\end{array}$ \\
\hline $\begin{array}{l}\text { Higher quality candidates } \\
\text { apply }\end{array}$ & Designing VCBI questions & $\begin{array}{l}\text { Candidates may be unaware } \\
\text { of VCBls }\end{array}$ & $\begin{array}{l}\text { Staff training and } \\
\text { development }\end{array}$ \\
\hline $\begin{array}{l}\text { Strong candidates can be } \\
\text { identified at interview }\end{array}$ & $\begin{array}{l}\text { Panel members may lack } \\
\text { experience of VCBls }\end{array}$ & $\begin{array}{l}\text { Candidates may need } \\
\text { guidance about VCBls }\end{array}$ & $\begin{array}{l}\text { Post-interview reflections } \\
\text { by panel members }\end{array}$ \\
\hline $\begin{array}{l}\text { Improved quality of } \\
\text { interviews }\end{array}$ & VCBls can take more time & $\begin{array}{l}\text { Line managers are not } \\
\text { included in panels }\end{array}$ & $\begin{array}{l}\text { Inclusion of successful } \\
\text { candidates' line managers } \\
\text { in panels }\end{array}$ \\
\hline Empowered panel members & $\begin{array}{l}\text { Non-attendance of } \\
\text { candidates }\end{array}$ & $\begin{array}{l}\text { Panel members should be } \\
\text { trained in VCBI }\end{array}$ & $\begin{array}{l}\text { Development of a forum for } \\
\text { panel members to share } \\
\text { VCBI questions }\end{array}$ \\
\hline $\begin{array}{l}\text { 'Best fit' candidates can be } \\
\text { selected }\end{array}$ & $\begin{array}{l}\text { Struggling candidates may } \\
\text { need guiding }\end{array}$ & & Long-term follow up \\
\hline
\end{tabular}

One participant noted: 'The answers you get from staff predict how they'll perform in the future. You're learning (about them) from their past experiences.'

\section{A3. Improved overall quality of interviews Asking probing questions, such as 'can you explain your actions and the result a little further?', to focus on specific answers improved the quality of the interviews, while participants recognised that asking candidates to discuss real-life situations prevented their responses from stagnating. One participant said: 'With the previous interview format I have been shocked at some of the questions that were asked. They did not get to the core of what was meant to be happening.'}

\section{A4. Empowered panel members}

Interview panel members felt empowered to appoint, or not appoint, candidates based on their VCBI. They had received training that reinforced good interview techniques and the VCBI scoring system. For example, one participant said: 'At a recent interview our panel chair told us that the first thing she would look for from candidates is clinical skills so that they can hit the ground running. But clinical skills can be taught, so at the end of the interview we employed someone who did not necessarily have all the necessary clinical skills at that time, but who had the qualities, care and compassion that we were looking for. Another candidate had the clinical skills but not the right caring attitude... we would not have picked that way before.'

\section{A5. Selection of the "best-fit" candidate} Participants felt that the scoring system consistently identified the best candidates. Discussion among the interview panel, after scoring, supported selection of the person who was perceived as the best-fit for the job. During the focus groups, this led to discussion about the importance of having team leaders and/or line managers on interview panels.

Senior leaders stressed the importance of selecting individuals with the right attributes to perform well in their team. They also discussed the complexity of human relationships, highlighting the need to consider 'character' in relation to how this could positively affect specific teams.

\section{Theme B: Challenges of using VCBIs}

Although all participants viewed VCBIs positively, they also identified five challenges.

\section{Bl. Designing VCBI questions}

Interview panel members found it difficult to design questions that captured all the qualities required for the post. One said: '...personally that's what I find the most challenging...

finding the right questions... As the interview goes on you have your set questions and you'd just love to change them but you need to be consistent and fair.'

Some panel chairs shared strategies to improve the choice of questions, which included meeting with the interview panel beforehand to collectively choose suitable questions, reading questions aloud to determine if they could be understood by

\section{Related articles}

Preparing nurses to work in primary care: educators' perspectives. Nursing Standard. doi: $10.7748 / \mathrm{ns}$ 2013.05.27.36.41.e7085

Assessment of practitioners' and students' values when recruiting. Nursing Management. doi: $10.7748 /$ $\mathrm{nm}$.21.5.22.el252

Organisational commitment in nurses: is it dependent on age or education? Nursing Management. doi: 10.7748/ $\mathrm{nm}$.21.9.29.el298 


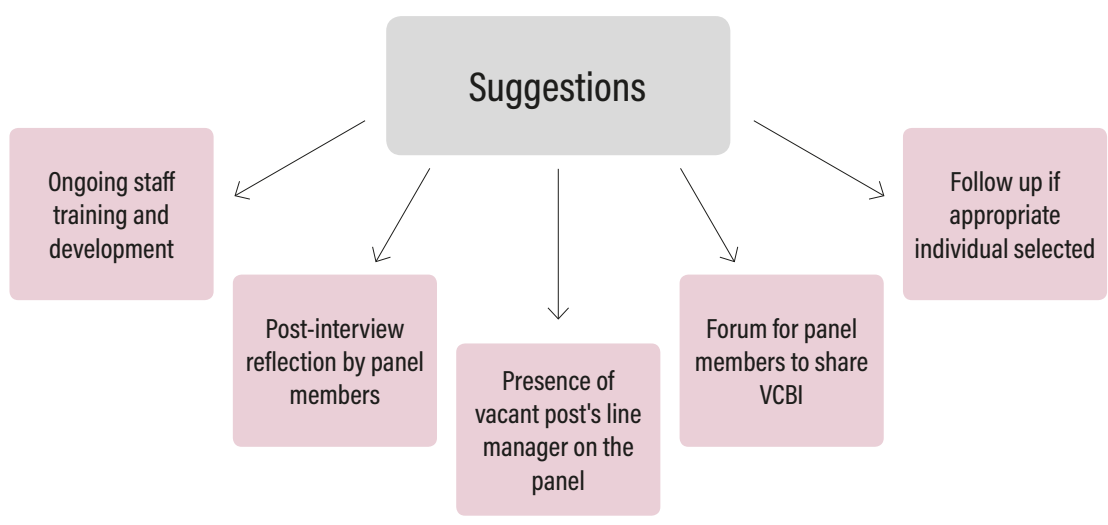

candidates, and selecting panel members to ask specific questions. For example, one commented: 'I used to choose the questions [as the chair] and discuss with the panel. But what we do now is meet half an hour earlier and choose the questions together, which is much better as it makes us all familiar with the questions.'

It was also considered important to ask questions that matched the competencies required for the post.

\section{B2. Experience of interview panel}

Effective delivery of the VCBI relied on the panel members' experience. Panel members identified challenges as they gained experience, for example: 'I found I was stilted at first. I very much stuck to my questions. I found it different to what I was used to.'

The role of the panel chair was considered particularly important in ensuring that interviews focused on values and competencies. Their skills in encouraging candidates to use personal scenarios, and guiding discussions about their 'individual' contributions to those scenarios, were considered integral to the overall quality of the interview. One participant said: 'You need to be a very good interviewer to pull the behaviours out to get a demonstration to say "you're a great communicator". Because often at an interview you [panel chair] might reflect back and say "I didn't even ask them that question, how can I score this?" You need to be very good at interviewing to pull that behaviour out.'

HR participants described how they encouraged the interview panel to reflect on and evaluate their own performance, within the panel member guidelines, at the end of interviews. The purpose of reflection was to provide opportunities for skill development, particularly on interview questions and style. Some panel chairs found the exercise helpful. An HR participant said: 'If somebody could sit in and give them [the interview panel] feedback. We [HR] try to encourage that in the panel chair's guide... they are encouraged to sit back and reflect at the end of the interview... and to hone their skills better.'

\section{B3. Preparation time for the interview} Adequate preparation was highlighted by HR participants as the main component of an efficient interview process, but the time this could take was reported as a challenge. Time allocated by HR for interviews is 45 minutes across all band levels. Some participants said this resulted in significant time away from their clinical areas, and that time allocation should vary according to the level of post or band.

This was contested by some panel chairs, who argued that staff in band 2 onwards are all 'front line', suggesting that significant time should be invested in ensuring staff at all levels have the required values and competencies.

One participant noted that 'the timing is a challenge. If you're doing band $5 \mathrm{~s}$ and $6 \mathrm{~s}$, you need about 45 minutes. But actually if you're doing a band lower than that you'll need less....', while another commented: 'Bands 2, 3 and 4 are our front line staff. These are the people that are the face of the NHS. Patients meet them as soon as they come into hospital, so it is so important that these staff are well chosen.'

\section{B4. Non-attendance by candidates} Candidates who failed to attend for interviews caused significant gaps in the schedule, and there was frustration about the ineffective 
use of time when this happened. Several participants suggested that HR should consider ways of managing applications from candidates who had not attended two previous interviews, and argued that this could be perceived as a measure of their values: 'We've written to HR and asked them to not invite them to interview again if they have missed an interview twice.'

\section{B5. Guiding struggling candidates}

Participants reported that some candidates struggled with the VCBI format. But reassuring them, and providing guidance and prompts about what was expected, helped them relax and perform to a higher standard: 'I'd say some candidates struggle with it. I tend to say "take a minute, give yourself time to think of a really, really good example".'

Equality and diversity were identified as the most challenging questions for candidates to answer, and some panel chairs chose to ask these towards the end, to avoid interviews starting poorly. One person said 'Candidates seem to struggle with equality and diversitybased questions', while another added: 'I tend to move equality and diversity to the end because people find it difficult.'

\section{Theme C: Limitations of using VCBIs}

Although the overall experience of using VCBIs was positive, participants highlighted some limitations.

\section{Cl. Candidates' lack of awareness of VCBIs} Some candidates appeared to lack awareness and understanding of what was required to succeed at a VCBI, and many failed to describe specific examples of their values and competencies at the application stage. This meant that many applicants did not give enough information to be selected for interview. Candidates also appeared to be unprepared for VCBI questions during their interview, and some required guidance on how to respond.

This issue was particularly noticeable among recent graduates. Participants from the senior leaders' focus groups discussed how they tried to resolve this problem by delivering information sessions to health professional students. However, it was noted that these 'interview skills' training sessions were not compulsory. One participant said: 'On the back of that I've gone out to meet the final year students and say "There's nothing in this application that lets me know who you are. Put all your voluntary and previous work experience in".'
C2. Provision of VCBI guid ance to candidates HR staff said candidates were provided with guidance in their application pack, which is an online link with an interview letter, and were informed at the start of their interview that the panel would use a VCBI format. However, some candidates remained unclear or unaware of what was expected. It was suggested that guidance could perhaps be signposted more effectively, and should emphasise the importance of preparation.

\section{C3. Absence of line managers on interview} panels

There was enthusiastic discussion about the use of 'cohort interviews', which are hospital or community site-based interview days for multiple candidates applying for posts at a particular site and/or in a particular specialty. However, the absence of a line manager, such as a team leader or senior charge nurse, on cohort interview panels was perceived as a limitation. Although it was agreed that VCBIs identified high quality candidates, participants said that line managers could then select the 'best-fit' for their team from this group.

\section{C4. Use of trained panel members} Participants perceived an imbalance in the use of panel members and chairs who had participated in VCBI training. A large number of healthcare professionals have now been trained in using VCBIs, but there was general agreement that a small number were used repeatedly on panels. This led to an imbalance in the number of panel members and chairs who were building experience and confidence. Some participants expressed a wish to be more involved so that they did not lose their VCBI skills: '... they've done the training, but never been given the opportunity to put it into practice. It's like passing your driving test then not being allowed to drive.'

\section{Theme D: Future refinement of VCBIs}

At the end of each focus group and interview, participants suggested ways in which VCBIs could be improved to strengthen selection, and these are illustrated in Figure 1.

\section{Feedback from interview candidates}

In all, 12 candidates provided feedback using the anonymous post-interview questionnaire (Figure 2). Overall, they perceived their VCBI experience as positive and welcomed the new style of interview. Candidates who had undertaken a second VCBI $(50 \%)$ had clearer expectations of the process, and found the interview more comfortable.

\section{KEY POINT}

Participants reported that some candidates struggled with the VCBI format. But reassuring them, and providing guidance and prompts about what was expected, helped them relax and perform to a higher standard 


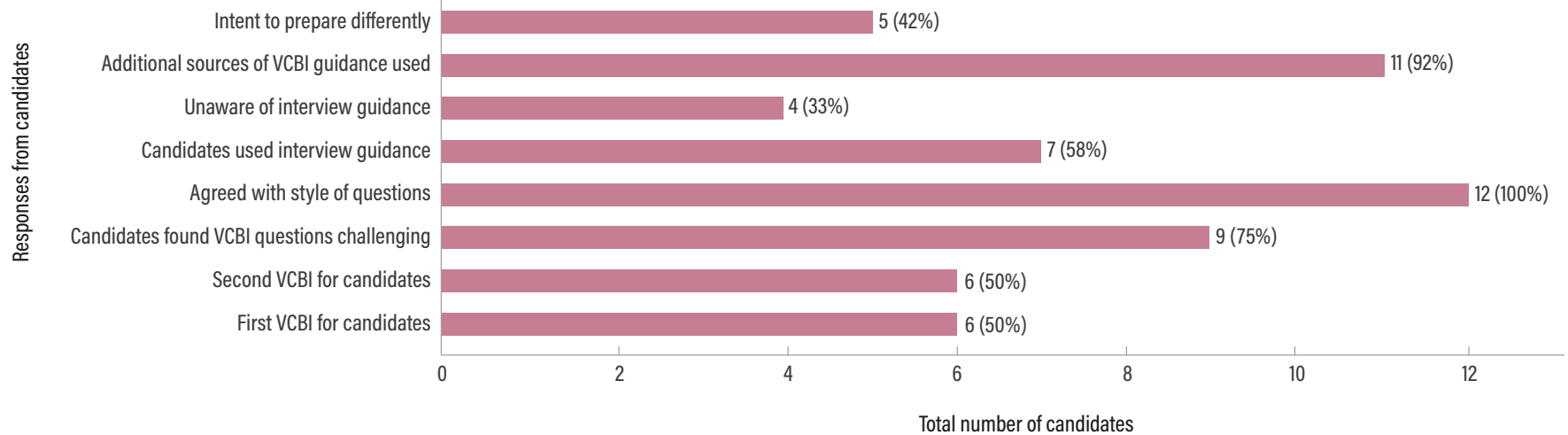

\section{Discussion}

The findings from this study support evidence that suggests VCBIs are robust and provide a more rigorous method of selecting the best candidates (Gangani et al 2006). And it is encouraging that the benefits are similar to those cited in recent literature, for example that higher quality candidates are selected at both application and interview stages (Health Education England 2014).

A strength of VCBIs is their ability to assess candidates consistently against a competency framework (Nelson 2004), and the framework used in NHS Lanarkshire (2013b) incorporates many of the values associated with modern health care, including empathy, care, compassion and equality. Panel members highlighted that they felt empowered to make decisions based on candidates' clinical competencies and personal values. It appears that the framework provides greater transparency in the selection process, as well as consistency in candidate feedback.

Participants agreed that VCBIs help identify the strongest candidates, but they also said that direct line managers should play a main role on interview panels in terms of selecting the 'best-fit'

\section{BOX I: Tips for applicants}

Prepare to be asked for examples of your reactions to real-life situations

" Think of situations you have successfully faced, where you can demonstrate results achieved

"Prepare answers using the Star approach: Situation, Task, Action, Result

» Do your best to use the word 'I'. What you did may have been a team effort, but it is important to highlight your personal contribution

» Prepare for questions which begin: 'Can you give an example of...,' Tell me about a time when...', or 'Describe a situation in which...'

» Be ready to give more detail after answering a question. Interviewers often 'probe' to get as much evidence from you as possible

» Learn from the experience, regardless of the interview outcome. Ask yourself which answers you were happy with, which gave you the most difficulty and why, and how you could have been better prepared (Tips adapted from NHS Lanarkshire 2015) for their clinical teams. Several challenges and limitations were identified, which mainly related to panel members' experience of taking part in VCBIs, and candidates' preparation. Panel members and chairs all agreed that their VCBI questioning skills improved with experience. Training in VCBI techniques was considered valuable and helpful but should be followed up with experience over the following few months.

Interview panel members found designing effective VCBI questions challenging. One suggested there should be an opportunity to share interview questions that seemed to work well, or did not work well. This approach is in use in large organisations that improve efficiency of VCBIs by sharing selection tools and processes online, such as competencybased guidance that is available to the public, and question banks for interviewers (Nottingham Trent University 2014).

Candidates who had already participated in one VCBI found their next interview more comfortable, which suggests their performance also improves with experience. Although candidates received VCBI guidance, panel members felt many still seemed unprepared. This was also reflected in the candidates' feedback, in which a third said they were unaware of the guidance provided by HR. Therefore, it could be useful for HR to revise VCBI guidance signposting, and to emphasise the importance of preparing for this type of interview to improve overall quality.

Finally, recent reports have highlighted the importance of improving selection processes specifically for newly qualified nurses (Willis Commission 2012, Francis 2013). However, research shows that job descriptions and competency frameworks for newly qualified nurses often focus on clinical competencies and lack assessment of applicants' characters (Burke et al 2014, Newton et al 2014). 
A web-based resource, Flying Start, provided by NHS Scotland to newly qualified NMAHPsw, supports the transition from student to employee (NHS Education for Scotland (NES) 2014a), and encourages the use of values-based reflective practice, which encompasses issues related to VCBIs (NES 2014b). To support developments in the use of VCBIs, Boxes 1 and 2 offer some tips for applicants and panel members.

\section{Study limitations}

At the time of the research, 65 senior leaders had received training in the use of VCBIs. However, this study reported the experiences of 21 staff who had been involved in VCBIs, and might not reflect all experiences. The study would also benefit from observation of the VCBIs for protocol fidelity, such as 'is the panel using appropriate values and competency-based questions?’

Candidate feedback was collected from 12 participants, which again does not reflect a wide range of perspectives. Therefore, further evaluation is needed to explore the long-term effects of this interview technique on the quality of the workforce.

\section{Conclusion}

Using VCBIs was regarded overall as a positive change in the NMAHP selection process, and ultimately this approach could positively affect the quality of the healthcare workforce. Refinement of the process should focus on

\section{BOX 2: Tips for panel members}

» Be consistent in reviewing applications, considering criteria appropriate to the role

» Meet in advance to agree format, structure and competency-based questions

» Have the role's desirable competencies in mind when framing questions

» Use open questions to ask candidates about their approach, behaviour and achievements

» Avoid jargon. Try 'Tell me about...,' Talk me through...,' 'Give an example of...'

» Avoid hypothetical questions. The aim is to find out about candidates' experiences and behaviour

» Put applicants at ease by using a friendly, welcoming approach. Consider your body language, for example maintaining eye contact

» Review your performance, and that of other panel members (Tips adapted from NHS Lanarkshire 2013b)

developing interview panel members' VCBI skills and experience.

Other practice areas could consider implementing this method of selection, to help identify and appoint staff with the appropriate values for working in healthcare settings.

Since this study was completed, more work has been undertaken to ensure effective implementation, and further research is planned to identify the extent to which the most appropriate candidates are selected.

The positive experiences of panel members and chairs, HR staff and interview candidates reported here could support and inform leaders and managers in a review of their selection processes. The findings also contribute to the growing evidence base on values-based selection.

Finally, the delivery of high quality patient care set the foundation of this study, and remains a vital aim of VCBI development.

\section{Write for us}

journals.rcni.com/r/ $\mathrm{nm}$-author-guidelines

\section{References}

Burke L, Sayer J, Morris-Thompson T et al (2014) Recruiting competent newly qualified nurses in the London region: an exploratory study. Nurse Education Today. 3, 10, 1283-1289.

Cerinus M, Shannon M (2014) Improving staff selection processes. Nursing Standard. 29, 10 37-44.

Colaizzi P (1978) Psychological research as the phenomenologist views it. In: Valle R, King M (editors) Existential Phenomenological Alternatives for Psychology. Oxford University Press, New York NY.

Ersoy N, Altun I (1998) Professional and persona values of nursing in Turkey. Eubios Journal of Asian and International Bioethics. 8, 3,72-83.

Francis R (2013) Report of the Mid Staffordshire NHS Foundation Trust Public Inquiry - Volume 3: Present and Future. The Stationery Office, London.

Gallagher A (2004) Dignity and respect for dignity two key health professional values: implications for nursing practice. Nursing Ethics. 11, 6, 587-599.

Gangani N, McLean G, Braden R (2006) A competency-based human resource development strategy. Performance Improvement Quarterly. $19,1,127-139$.
Gutierrez A, Candela L, Carver L (2012) The structural relationships between organizational commitment, global job satisfaction, developmenta experiences, work values, organizational support, and person-organization fit among nursing faculty. Journal of Advanced Nursing. 68, 7, 1601-1614.

Hall J (1996) Nursing Ethics and Law. Saunders, Philadelphia PA.

Health Education England (2014) Evaluation of Values-Based Recruitment (VBR) in the NHS. NHS Health Education England, London.

Highhouse S (2008) Stubborn reliance on intuition and subjectivity in employee selection. Industrial and Organizational Psychology. 1,333-342.

King's Fund (2013) Patient-Centred Leadership: Rediscovering Our Purpose. King's Fund, London

McGuire C, Ray D (2014) Developing leadership roles in nursing and midwifery. Nursing Standard. $29,9,43-49$

Nelson G (2004) Hiring the complete nurse: selecting the right nurses means looking beyond clinical skills. Nurse Leader. 2, 36 .
Newton P, Chandler V, Morris-Thomson T et al (2014) Exploring selection and recruitment processes for newly qualified nurses: a sequential-explanatory mixed-method study. Journal of Advanced Nursing. $71,1,54-64$.

NHS Education for Scotland (2014a) Flying Start NHS. www.flyingstart.scot.nhs.uk (Last accessed: 24 September 2014.

NHS Education for Scotland (2014b) Values Based Reflective Practice in Flying Start NHS. tinyurl.com/ zghutot (Last accessed: 29 September 2014.)

NHS Lanarkshire (2013a) Values and Competencies for Nurses, Midwives and Allied Health Professionals. NHS Lanarkshire, Bothwell.

NHS Lanarkshire (2013b) A Guide to Value and Competency-Based Selection and Interviewing for Panel Chairs. NHS Lanarkshire, Bothwell.

Nottingham Trent University (2014) Competency Based Recruitment and Selection: A Guidebook for Managers. tinyurl.com/jj638cw (Last accessed: 15 November 2014.

Parliamentary and Health Service Ombudsman (2011) Care and Compassion? Report of the Health Service Ombudsman on Ten Investigations into
NHS Care of Older People. tinyurl.com/3rpp7no (Last accessed: 1 November 2014.)

Patterson F, Ferguson E, Thomas S (2007) Using job analysis to identify core and specific competencies: implications for selection and recruitment. Medical Education. 42, 12, 1195-1204.

Rankin B (2013) Emotional intelligence: enhancing values-based practice and compassionate care in nursing. Journal of Advanced Nursing. 69, 12 2717-2725.

Scottish Government (2013) 2020 Vision. SG, Edinburgh.

Smith R, Lagarde M, Blaauw D et al (2013) Appealing to altruism: an alternative strategy to address the health workforce crisis in developing countries? Journal of Public Health. 35, 1, 164-170.

Willis Commission (2012) Quality with Compassion, the Future of Nursing Education. Royal College of Nursing, London.

Yancey V (1997) Values and ethics. In: Potter P, Perry A (editors) Fundamentals of Nursing: Theory and Practice. Fourth edition. Mosby, St Louis MO. 